\title{
Data Collection on Spinal Cord Injuries: Urological Outcome
}

\author{
D. C. Burke, ${ }^{1}$ D. J. Brown, ${ }^{2}$ H. T. Burley ${ }^{3}$ and G. H. Ungar ${ }^{2}$ \\ ${ }^{1}$ Bethesda Hospital, 30 Erin St., Richmond, Victoria, 3121, ${ }^{2}$ Spinal Injuries Unit, \\ Austin Hospital, Studley Rd., Heidelberg, Victoria, 3084, ${ }^{3}$ School of Economics, \\ La Trobe University, Bundoora, Victoria, 3083, Australia
}

\section{Summary}

Analysis of 628 consecutive admissions to the Spinal Injuries Unit, Austin Hospital, between fuly 1978 and December, 1985 illustrates the value of a comprehensive data collection system which has been developed at the hospital since 1978.

Some brief epidemiological data is presented, together with a detailed analysis of the urological outcome of patients with traumatic lesions whose discharge has been completed. $A$ high rate of catheter-free status and urine sterility at discharge is reported, and factors affecting these results are analysed.

The authors hope that an international system of data collection can be developed in the future to allow meaningful comparison of results between units.

Key words: Data collection; Spinal cord injuries; Urological outcome.

\section{Introduction}

A detailed comprehensive system of data collection on spinal cord injuries has been developed at the Austin Hospital since 1978, has been previously described, together with an analysis of 352 consecutive admissions of patients with spinal cord injury to the Spinal Unit between July, 1978 and December, 1982, Burke et al. (1985, Part 1, Part 2). The programme, which has been supported by research grants, has been conducted in collaboration with La Trobe University, whose main frame computer stored and analysed the data.

This report further analyses the data to the end of 1985 on 628 consecutive admissions. Some of the epidemiological or personal data have been updated; the urological results in this series are analysed in more detail.

\section{Patients and methods}

On admission of the patient, as much personal and clinical material as is available at that time is entered on a data collection form by the senior doctor admitting 
the patient: the form is completed on discharge. The information is subsequently transferred to computer disc storage by one of the authors (H.B.). The form contains 308 variables, under six main categories. An average time of 1 hour per admission is not considered an onerous task for a senior doctor, considering the patients' average length of stay in hospital.

This analysis is of 628 consecutive first admissions of patients with spinal cord injuries to the Spinal Injuries Unit, Austin Hospital, between 1 July 1978 and 31 December 1985. The data was analysed in April, 1986, and some of the material has been reported in more detail at a recent conference (Burke, et al., 1986 , in press).

\section{Results}

\section{Personal data}

The annual number of admissions varied between 63 and 97, with a slight decline in the number in the past one year. Over $90 \%$ of the admissions followed trauma (Table I). Accidents occurred predominantly in the country, rather than in the metropolitan area, involving people who lived in the country out of proportion to the population distribution in Victoria (Table II), where over $75^{\circ}$ of Victorians live in metropolitan Melbourne.

Inpatient end status is shown in Table III. 'Normal discharge' excludes those who died or were transferred to another unit for continued rehabilitation,

Table I Aetiology, 1.7.78 to

$31.12 .85,628$ consecutive admission

\begin{tabular}{lc}
\hline Trauma & $582\left(92 \cdot 7^{\circ}{ }_{0}\right)$ \\
Non trauma & $36\left(5 \cdot 7^{\circ}{ }_{0}\right)$ \\
Hysteria & $10\left(1 \cdot 6^{\circ}{ }_{0}\right)$ \\
TOTAL & 628 \\
\hline
\end{tabular}

Table II Location of accident $\mathrm{X}$ location of residence. Traumatic admissions, 1.7 .78 to 31.12 .85

\begin{tabular}{lccc}
\hline Location of accident & \multicolumn{3}{c}{ Location of Residence } \\
\hline & Capital City & Country Town, Rural & Total \\
\cline { 2 - 4 } Capital city & $208\left(94 \cdot 1^{\circ}{ }_{o}\right)$ & $13\left(5.9^{\circ}{ }_{0}\right)$ & 221 \\
Country, rural & $102\left(30 \cdot 3^{\circ}{ }_{0}\right)$ & $235\left(69^{\circ}\right)$ & 337 \\
At sea & $2\left(0.7^{\circ}{ }_{0}^{\circ}\right)$ & $1\left(0 \cdot 3^{\circ}{ }_{0}\right)$ & 3 \\
\hline
\end{tabular}

Location of accident or home not recorded 21.

Table III Inpatient end status: 1.7 .78 to 31.12 .85

\begin{tabular}{ll}
\hline \multicolumn{1}{c}{ First admissions } & \multicolumn{1}{c}{628} \\
\hline Normal discharge & $415(69 \cdot 4 \%)$ \\
Transfer & 76 \\
Temporary accommodation & 58 \\
Death & $25(4 \cdot 2 \%)$ \\
Still inpatient & 24 \\
\hline
\end{tabular}

Missing observations 30 . 
that is, those whose 'end point' of rehabilitation was not reached in the Unit. About $70^{\circ}{ }_{0}$ of the patients were considered to be 'normal discharges', of whom only $4 \cdot 2^{\circ}{ }_{0}$ required nursing home or quadriplegic centre care, the balance returning home to live in the community.

\section{Clinical data}

Outcome of treatment has only been analysed for the 373 patients with lesions of traumatic origin, who were considered to be normal discharges. Excluded also were the small number with hysterical paraplegia, as these should be considered as 'non traumatic' even though a number followed trauma.

In $59\left(18.09^{\circ}{ }_{0}\right)$ of the patients, management of the fracture or fracture/dislocation was by a variety of surgical techniques; the balance were managed conservatively.

The relationship of neurological outcome to delay in admission has been reported elsewhere (Burke et al., 1986, in press). In summary, over $80 \%$ of patients were admitted within 24 hours of injury, $60 \%$ within 6 hours. No improvement in neurological outcome could be demonstrated by early admission to the Unit. As expected, patients with lesions incomplete on admission did better than those with complete lesions, but neurological improvement in $20 \%$ of lesions complete on admission raises questions about the adequacy of neurological examination on admission. Neurological status on discharge is summarised in Table IV, for 373 patients following trauma who had undergone normal discharge at the time of analysis. $79^{\circ}{ }_{0}$ of the patients were male. Noncervical lesions outnumbered cervical lesions. In both the cervical and noncervical groups, incomplete lesions outnumbered complete lesions at discharge.

Table IV Neurological lesion at discharge. Normal discharges, trauma, 1.7 .78 to 31.12 .85

\begin{tabular}{lccc}
\hline \multicolumn{1}{c}{ Neurological Lesion } & Male & Female & Total \\
\hline Complete cervical & 43 & 9 & 52 \\
Incomplete cervical & 82 & 18 & 100 \\
Complete non cervical & 64 & 13 & 77 \\
Incomplete non cervical & 77 & 32 & 109 \\
Unknown & 37 & 7 & 44 \\
TOTAL & 294 & 79 & 373 \\
\hline
\end{tabular}

The urological outcome on these 373 patients has been studied in detail.

The statistical method used to compare sample proportions involved the calculation of standard deviation. The computation of standard deviation of the difference between two sample proportions $P_{1}$ and $P_{2}$ in independent samples of size $n_{1}$ and $n_{2}$ is given by:

$$
S_{P_{1}-P_{2}}=\sqrt{\frac{P_{1}\left(1-P_{1}\right)}{n_{1}}+\frac{P_{2}\left(1-P_{2}\right)}{n_{2}}}
$$

Where cell sizes are, say $>5$, tables of the Standard Normal Distribution may be used to obtain these Binomial probabilities. 
The urological management of the patients was by indwelling, urethral catheterisation from the time of admission, converting to intermittent catheterisation not earlier than 10 days after injury in males, depending on staff availability. In females, intermittent catheterisation is often delayed until the patient is mobilised from bed. Occasional patients with very incomplete lesions are not catheterised, except on need.

Table $\mathrm{V}$ shows the urological management at discharge. $70^{\circ}{ }_{\mathrm{o}}$ of the patients were discharged catheter-free, with no significant difference between males and females. A significantly higher proportion of females, however, were discharged with an indwelling urethral catheter, and a significantly higher proportion of males on self-intermittent catheterisation.

Table V Urological status on discharge. Normal discharges, trauma, 1.7.78 to 31.12.85

\begin{tabular}{|c|c|c|c|}
\hline Urological Status & Male & Female & Total \\
\hline Catheter free & $208\left(71^{\circ}{ }_{0}\right)$ & $55\left(70_{0}^{\circ}\right)$ & $263\left(70 \cdot 5_{0}^{\circ}\right)$ \\
\hline Indwelling urethal catheter & $23\left(8_{0}^{0}\right)$ & $16\left(20_{0}^{\circ}\right)$ & $39\left(10.5^{\circ}{ }_{0}\right)$ \\
\hline Indwelling suprapubic catheter & $13\left(4 \cdot 5_{0}^{\circ}\right)$ & $3\left(4^{\circ}{ }_{0}\right)$ & $16\left(4_{0}^{\circ}\right)$ \\
\hline Intermittent catheterisation & $7\left(2 \cdot 5_{0}^{\circ}\right)$ & $1\left(1^{\circ}{ }_{0}^{\circ}\right)$ & $8\left(2^{\circ}{ }_{0}\right)$ \\
\hline Self intermittent catheterisation & $39\left(13_{0}^{0}\right)$ & $4\left(5^{\circ}{ }_{0}\right)$ & $43\left(11 \cdot 5_{0}^{\circ}\right)$ \\
\hline Other & $4\left(1_{0}^{\circ}\right)$ & 0 & $4\left(1{ }^{\circ}{ }_{0}\right)$ \\
\hline Total & 294 & 79 & 373 \\
\hline
\end{tabular}

Table VI Urological procedures performed on males. Normal discharges, trauma, 1.7 .78 to 31.12 .85

\begin{tabular}{lc}
\hline External sphincterotomy & $33\left(58.9^{\circ}{ }_{0}\right)$ \\
Cystoscopy & 16 \\
Litholopaxy & 12 \\
Formal suprapubic catheter & 8 \\
TUR bladder neck & 4 \\
Other & 6 \\
\hline Total & 56 \\
\hline
\end{tabular}

Table VI lists the 56 surgical urological procedures performed on male patients. Cystoscopy is considered as a surgical procedure in this paper. The most common surgical operation was external urethral sphincterotomy. Some patients, of course, had more than one procedure. Cross analysis shows that those who had an external sphincterotomy were more likely to be catheter-free at discharge, compared to those on whom other urological procedures were performed. Not surprisingly, litholopaxy was more common in those with some form of catheter drainage at discharge, especially by indwelling catheter.

Infection was taken as the presence of more than 10,000 leucocytes per $\mathrm{mm}^{3}$, with a positive culture. Patients are routinely commenced on Mandelamine $1 \mathrm{~g}$. q.i.d. and Ammonium Chloride 1g. q.i.d. soon after admission. Antibiotics are only used when clinically indicated. As a measure of urological outcome, those with infected urine on discharge were analysed with respect to a number of variables. Table VII shows the percentage of these patients, by year. The annual incidence of these varied between $7^{\circ}{ }_{0}$ and $37^{\circ}{ }_{0}$. A Chi-square analysis of the 
Table VII Infected urine at discharge X year. Normal discharges, trauma, 1.7.78 to 31.12 .85

\begin{tabular}{lccccccccc}
\hline & $\begin{array}{c}1978 \\
(\mathrm{~J}-\mathrm{D})\end{array}$ & 1979 & 1980 & 1981 & 1982 & 1983 & 1984 & 1985 & Total \\
\hline $\begin{array}{c}\text { Number } \\
\quad \text { infected }\end{array}$ & 0 & 17 & 7 & 12 & 8 & 4 & 8 & 4 & 60 \\
Percentage & 0 & 37.0 & 13.5 & 21.8 & 11.4 & 7.5 & 13.1 & 10.5 & 15.4 \\
\hline
\end{tabular}

Table VIII Infected urine at discharge $\mathrm{X}$ neurological lesion. Normal discharges, trauma, 1.7.78 to 31.12 .85

\begin{tabular}{llcc}
\hline & & Number & Percentage \\
\hline Complete & (A) & 36 & 29.3 \\
Sensory sparing & (B) & 10 & 28.6 \\
Motor useless & (C) & 5 & 22.7 \\
Motor useful & (D) & 7 & 6.5 \\
Normal & (E) & 2 & 1.9 \\
\hline
\end{tabular}

table of infection by year (ignoring 1978, when infection was not recorded) is not quite significant at the $5_{0}^{\circ}$ level.

In comparing male and female infection rates, sex alone was not a statistically significant factor. Our statistically small female sample size does not permit us to draw any firm conclusion. The same applies in relating urinary infection to age, as there were only 60 infected patients.

Table VIII relates neurological lesion to urinary infection at discharge and shows infection to be much more common in the more severely impaired groups than in those with very incomplete or no neurological lesions. The grade of lesion is therefore very significant in determining urinary infection $\left(\chi^{2}=44\right.$ at $4^{\circ}$ of freedom), having a probability of less than 0.00001 .

Analysis of infection in relation to bladder management at discharge shows a high incidence of infection in those with an indwelling catheter $(70.2 \%)$ compared to $7 \cdot 2^{\circ}$ o in those discharged with no form of catheterisation. Figures for those with other methods of catheterisation are too small to draw conclusions.

Analysis of urinary infection by neurological lesion and sex shows, after allowing for lesion grade, that the female infection rate his higher than the male. Cross analysis of urinary infection by sex and urinary management confirms that the difference in infection rate between females and males is related to the different methods of urinary management, in particular the higher proportion of females requiring an indwelling urethral catheter.

Table IX Delay in onset of urinary infection $\mathrm{X}$ sex $\mathrm{Y}$ lesion. Normal discharges, trauma, 1.7 .78 to 31.12 .85

\begin{tabular}{lcc}
\hline \multicolumn{3}{c}{ Days (Median) between injury and first infection } \\
\hline & Male & Female \\
Complete lesion & 18.39 & 4.69 \\
Incomplete lesion & 26.97 & 9.04 \\
\hline
\end{tabular}


Table IX has been constructed by using survival curve analysis for urinary infection in males and females. It shows very clearly that females become infected much earlier than males, both in those with complete and incomplete lesions. The survival curves also show that patients with complete lesions become infected earlier than those with incomplete injuries. It is also of interest to note that only three patients (all male) with complete lesions, but 39 (one female) with incomplete lesions, were never infected, after an average hospital stay of 91.4 days.

\section{Discussion}

The data collection system which has been developed at the Austin Hospital over the past 7.5 years now includes over 600 consecutive admissions to the Unit. It contains a wealth of important data on spinal cord injuries, which would have taken months to extract manually from patient files. Analysis of the data has enabled regular surveillance of the incidence of spinal cord injuries in Victoria, with an ability to detect trends in cause of injury: epidemiological information which has been of great application to programmes of treatment and prevention, as well as the planning of treatment services. The information has been available quickly, as required by government and other interested bodies or individuals.

The information collected has also been useful as an ongoing self audit of the Unit's performance, permitting regular monitoring of outcome of treatment programmes, including incidence of complications such as urinary infection, length of stay, outcome of rehabilitation, etc.

In addition, the data has allowed indepth analyses, such as has been presented here, to study the outcome of the Unit's urological programme, or the neurological outcome, which was recently presented elsewhere. Spinal stability is another clinical outcome which can readily be analysed.

The data presented is only a fraction of the information collected in the system. The results reported serve to illustrate the value of such a data collection system in the detailed analysis of a large series of patients, offering great opportunities for research.

It has long been the dream of the authors eventually to contribute to an international data bank on spinal injuries. The system is currently being reevaluated in a transfer from a research tool to a normal administrative function of the Unit, and it is planned to extend the data collection into follow-up after discharge from the initial admission. Efforts to extend the system to other Australian units have so far been unsuccessful, with one exception. The data collection system described by Young et al. (1982), which was extended to 17 Regional Spinal Injuries Units in the United States, did not go into as much detail as the one developed in Melbourne. It is to be hoped that compromises can be reached in the future so that we can all look forward to a truly international system of data collection which will allow meaningful comparison of results.

\section{Acknowledgement}

The authors wish to thank the Royal Australasian College of Surgeons, Road Trauma Committee, and La Trobe University for their support of this research programme. 


\section{References}

Burke DC, Burley HT, Ungar GH (1985) Data on Spinal Injuries-Part I. Collection and analysis of 352 consecutive admissions. Australian and New Zealand fournal of Surgery, 55, 312.

Burke DC, Burley HT, Ungar GH (1985) Data on Spinal Injuries-Part II. Outcome of the treatment of 352 consecutive admissions. Australian and New Zealand fournal of Surgery, 55, 377-382.

Burke DC, Brown DJ, Burley HT et al. (1986) Data Collection. Knowing what we are talking about. Presented at a conference, 'Ten Years of Spinal Research', in Hobart, Australia, May 1986. In press.

Young JS, Burns PE, Bowen AM et al. (1982) Spinal Cord Injury Statistics. Experience of the Regional Spinal Cord Injury System. Good Samaritan Medical Center, Phoenix, Arizona. 